\title{
Recurrent Acute Myelomonocytic Leukemia
}

National Cancer Institute

\section{Source}

National Cancer Institute. Recurrent Acute Myelomonocytic Leukemia. NCI Thesaurus.

Code C156717.

The reemergence of acute myelomonocytic leukemia after a period of remission. 